\title{
Power Quality Improvement for Matrix Converter using Shunt Active Filter
}

\author{
P.JenoPaul, I. Jacob Raglend, T.Ruban Deva Prakash and. R.PriyaDarsini \\ Noorul Islam University, Electrical and Electronics Engineering, \\ Tamilnadu, India
}

\begin{abstract}
This paper proposes a shunt active filter to minimize the power quality impact instead of using the conventional fixed Filters of the matrix converters. Matrix converters inject significant harmonics and nonstandard frequency components into power systems. The proposed approach eliminates the total line current harmonics efficiently. By minimizing the Total Harmonic distortion the harmonic pollution in the power system will be reduced, and the power quality will be increased. The proposed approach has been tested and validated on the matrix converter using Mat lab/Simulink. The Simulation results are shown to demonstrate the advantages of the proposed scheme.
\end{abstract}

Keywords-Matrixconverter ,Shunt active filter,Power quality,Current harmonics

\section{INTRODUCTION}

The matrix converter with $3 \emptyset$ to $3 \varnothing$ configuration is one of the possible direct AC-AC converter topologies [1].Matrix converter has several advantages over traditional rectifierinverter type power frequency converters. It provides sinusoidal input and output waveforms. It has inherent bi-directional energy flow capability and the input power factor can be fully controlled. Last but not least, it has minimal energy storage requirements, which allows to get rid of bulky and lifetimelimited energy-storing capacitors. In spite of the advantages ,the matrix converter has also some disadvantages. It has a maximum input output voltage transfer ratio limited to $\cong 87 \%$ for sinusoidal input and output waveforms. It requires more semiconductor devices than a conventional AC-AC indirect power frequency converter, since no monolithic bi-directional switches exist and consequently discrete unidirectional devices, variously arranged, have to be used for each bi-directional switch. It is sensitive to the disturbances of the input voltage system. But it will particularly produce higher order harmonics [2]. The matrix converter consists of 9 bi-directional switches thatallow any output phase to be connected to any input phase. The general architecture of the matrix converter is shown in Fig.1. Nine bi-directional switches in the matrix converter can theoretically assume $512 \quad\left(2^{9}\right)$ different switching states combinations. But not all of them can be usefully employed. Regardless to the control method used, the choice of the matrix converter switching states combinations (from now on simply matrix converter configurations) to be used must comply with two basic rules.

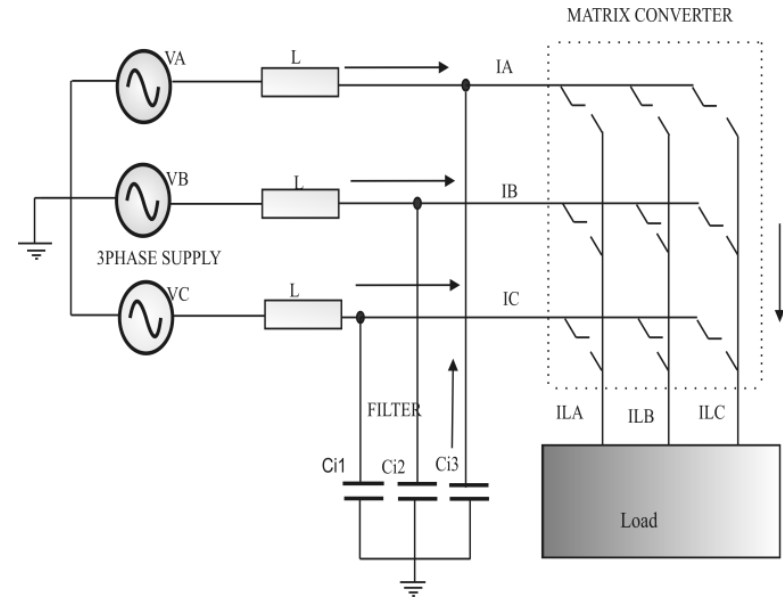

Fig. 1 General Architecture of Matrix Converter

Taking into account that the converter is supplied by a voltage source and usually feeds an inductive load, the input phases should never be short-circuited and the output currents should not be interrupted. From a practical point of view these rules imply that one and only one bi-directional switch per output phase must be switched on at any instant. By this constraint, in a three phase to three phase matrix converter only 27 switching combinations are permitted.

\section{POWER QUALITY ISSUES IN MATRIX CONVERTER}

\subsection{Power Quality}

Power quality is the set of limits or conditions of electrical properties that allows electrical devices to function in their planned manner without loss of performance. Without the proper power, an electrical utility or load may malfunction, fail permanently or not operate at well. There are many possible ways in which electric power can be poor quality. Ideally, voltage is fed by a utility as a sinusoidal wave is having a magnitude and frequency given by national, international standards or system specifications with impedance of zero ohms at all frequencies. Generally electrical power source is ideal and it can deviate in the following ways .Variations in the peak or RMS voltage are important to different types of equipment and load. When the RMS voltage goes beyond the nominal voltage by 10 to 80 percent for 0.5 cycles to 1 minute, the phenomena is called a "swell" [3]. "Sag" is the opposite action: the RMS voltage goes below the rated voltage by 10 to 90 percent for 0.5 cycles to 1 minute [4]. Variations in the wave shape usually known as harmonics [5]."Overvoltage" occurs when the nominal 
voltage increases above $110 \%$ for more than 1 minute [6]. "Under voltage" occurs when the nominal voltage fall or below $90 \%$ for more than 1 minute [7].

\subsection{Harmonics}

Harmonic is defined as "A sinusoidal component of a periodic wave having a frequency that is an integral multiple of the fundamental frequency" [8]. Therefore, harmonic is the presence of voltage/current with the frequency of a multiple of fundamental voltage/current in the voltage/current of the system. For example, a waveform with $60 \mathrm{~Hz}$ fundamental frequency and fifth $(300 \mathrm{~Hz})$, seventh $(420 \mathrm{~Hz})$, eleventh $(660 \mathrm{~Hz})$, and thirteenth $(780 \mathrm{~Hz})$ harmonics. For the metering and comparison of harmonic contents of waveforms, a parameter defined as a total harmonic distortion (THD). THD is defined for both current and voltage as given in equation(1)and (2).

$$
\begin{aligned}
& \text { For voltage: } T H D v=100 \sqrt{\frac{v_{h}^{2}}{v_{1}}} \\
& \text { For current: } T H D i=100 \sqrt{\frac{i_{h}^{2}}{i_{1}}}
\end{aligned}
$$

Where $I_{h}$ and $V_{h}$ are current and voltage harmonics, respectively. $I_{1}$ and $v_{1}$ are fundamental frequency of voltage and current .There are many nonlinear loads drawing no sinusoidal currents from electrical power systems. These no sinusoidal currents pass through different impedances in the power systems and produce voltage harmonics. These voltage harmonics propagate in power systems and affect all of the power system components. The important harmonic source is ac/dc converters/inverters. Many low-power single-phase converters/inverters and high-power three phase converters/inverters are being used in electrical power systems. If the number of converter/inverter pulses is $p$, then the order of harmonic current in AC side will be $n p \_1$ ( $n \_1$, $2,3 \ldots)$.

\subsection{Effects of Harmonics}

Except devices such as ovens and furnaces, which produce heat, most of the other electrical loads are sensitive to harmonics. In fact, harmonics may lead to their improper operation. Passing harmonic currents through the transmission lines cause interference with the communication circuits near the transmission lines and may cause a malfunction in these circuits. On the other hand, harmonic cause disturbance in sensitive loads in power systems such as sensitive medical devices, control circuits, and computers [9]. Control circuits that work on current or voltage zero crossing have higher sensitivity to harmonics and may not work properly in the presence of harmonics. Next issue is the loss in the power transmission lines. It can be expressed as

$$
P \text { Loss }=R I^{2}
$$

Where $R$ is the AC resistance of the transmission line and $I$ is the RMS value of the line current. If the current includes harmonics, then

$$
I_{2}=I_{1}^{2}+\sum I_{H}^{2}
$$

And then

$$
\text { PLoss }-h=R
$$

Although the harmonic currents cannot apply active power to the loads, they cause higher losses in the transmission lines. Harmonics also cause higher losses in power transformers, which are proportional to the square of the harmonic amplitude. Excessive losses and torque fluctuation also appears in electric motors in the presence of harmonics because only the fundamental component yields average torque in motors and harmonics yield core losses and torque fluctuation [10].Another problem is the presence of current harmonics in electrical power systems that increases neutral currents. In this case, the most important part of the neutral current is the third harmonic. Higher neutral currents, in four-wire, three-phase systems, in addition to the increasing size of the neutral wire, can cause overloaded power feeders, overloaded transformers, voltage distortion, and common mode noise. Another important problem caused by harmonics is resonance in power circuits. Current and voltage harmonics, which are produced by nonlinear loads, when passing through the power system or other load, may cause a resonance problem.

\subsection{Harmonic Production Prevention}

Changing and improving the characteristics of nonlinear devices can reduce the amount of produced harmonics. Improvements can be made in the two most harmonic-producing loads: converter/inverter systems and DC power supplies. Reduction of harmonic amplitude and low-frequency harmonic cancellation can be done by increasing the number of pulse in the converter/inverter systems. By changing the 6-pulse inverter to 12-pulse inverter, harmonics of order 5 and 7 are cancelled. Improving the DC power supply topology and control scheme improves the input current's harmonic spectrum. The use of boost, Cuk, single-ended primary inductor converter (SEPIC), and boost-integrated fly back rectifier/energy storage DC/DC choppers instead of buck, buck-boost, fly back, and forward converters may improve the quality of the input current Passive filters have been used for harmonic mitigation purposes for a long time. They consist of capacitors, inductors, and damping resistors. Passive filters, based on their characteristics, are divided into four categories: low pass, band-pass, high-pass, and tuned filters.. A band-pass filter (BPF) cancels the high- and low-order harmonics and passes a band of frequency. The tuned filter is designed to cancel one specific frequency. The increased severity of power quality problems and other problems associated with the passive filters such as large size and weight, higher cost, fixed compensation, and resonance problems with loads and networks has required a focus on a power electronic solution, that is, active filters. Nowadays, passive filters are used to cancel the switching frequency of active filters and high frequencies [11]. Tuned filters are used besides the active filters to cancel specific frequencies and decrease the power of active filters.

\subsection{The Passive input filter issue in matrix converter}

Although the matrix converter is sometimes presented as a silicon solution, due to the lack of the bulky and expensive DClink capacitors of traditional indirect frequency converter, it also requires a minimum of reactive components, represented by the input filter. The input filter acts as an interface between the matrix converter and the AC mains its basic feature is to avoid significant changes of the input voltage of the converter during each PWM cycle, and prevent unwanted harmonic currents from flowing into $\mathrm{AC}$ mains [12].Due to the discontinuous input 
currents, the matrix converter behaves as a source of current harmonics, which are injected back into the AC mains [13]. Since these current harmonics results in voltage distortions that affect the overall operation of the AC system, they have to be reduced. The principal method of reducing the harmonics generated by static converters is provided by the input filter using reactive storage elements as shown in fig [2]. The problem Fig2: Schematics Representation of the Basic Input Filter Configuration .(a)Capacitors connected in star.(b)LC filter with
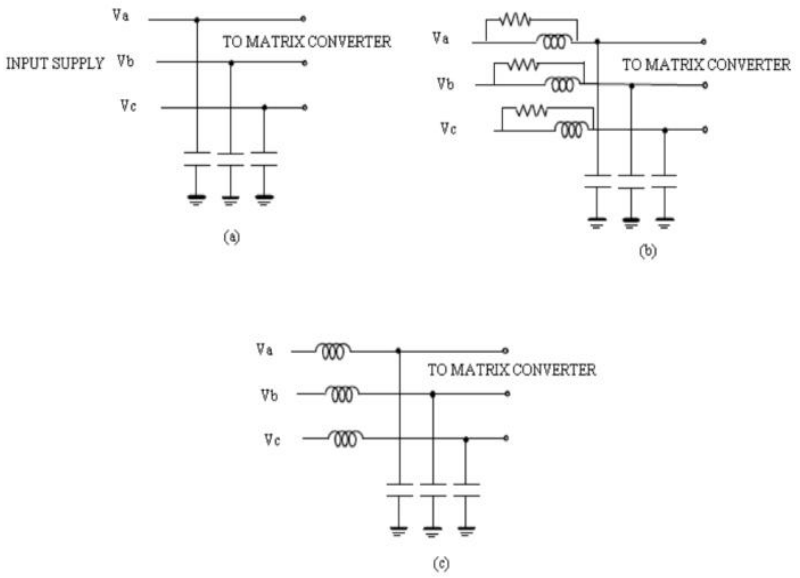

damping resistor.(c)Second order L.C filter type of the input filter design for a Matrix converter has been addressed in quite few papers [14], [15],[16] and looking at the literature, different configurations have been proposed for the matrix converter input filter [17], [18]. Such differences are a consequence of different design criteria, or at least differently weighted, different switching frequencies and different modulation strategies. In order to meet the required attenuation requirement, the filter inductor size increases, these results in the overall increases with filter size. Moreover, the input filter output impedance, related to the total filter capacitor value, is more difficult to control and leads converter instability. As far as the matrix converter is concerned, a high displacement angle of the input line current due to the input filter capacitance component might be compensated by the matrix converter, setting as reference for the input current a lagging displacement angle. But in this way the maximum voltage transfer ratio for the converter would be significantly reduced. Therefore, even for the matrix converter, the upper limit of the input filter capacitance is set by the minimum acceptable AC main power factor. Similarly the control of the impedance interaction between the input filter and the voltage converter is necessary. In general, the filters output impedance should be as low when compared to the converter input impedance. The filter output impedance can be reduced by the filter capacitor size may increase. Practically the impedance interaction constraint determines the lower constraint on the filter capacitor value. In addition to the above proper filter pole damping is extremely important for achieving low filter output impedance for all frequencies and, thus, overall system stability may be improved. In general, an optimized design of the matrix converter input filter is a quite difficult task, since it relies on a system level approach, and in the light of the new coming harmonic and EMI reduction standards it can be somehow considered as an outstanding issue.

\section{THE PROPOSED COMPENSATION SCHEME FOR MATRIX CONVERTER}

The most popular type of active filters is the shunt active filter. Shunt active filters can be single-phase or three-phase, voltage source or current source. Fig 3 shows the proposed compensation for matrix converter with a shunt active filter, source, and load. When the filter is used to compensate the current harmonics produced by the matrix converter, active filter compensates the harmonic current of a matrix converter, which produces harmonic current. In Fig. $3 Z_{s A}, Z_{s B}, Z_{s C}$ is impedances of the source and shunt passive filter, respectively. $I_{L h}, V_{L h}$, and $V_{s h}$ are the current harmonic of the load and voltage

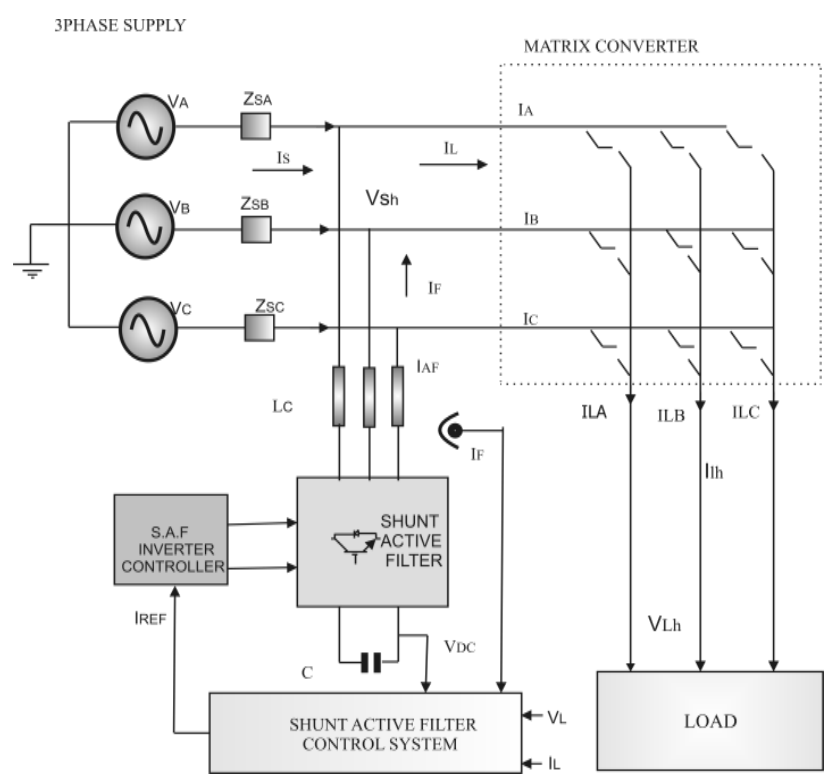

Fig 3: Proposed Compensation for Matrix Converter

harmonic of the load and source harmonics, respectively. $I_{A F}$ is the current of the shunt active filter. The control system design of the shunt active power filter for matrix converter cancel the harmonic in the supply current is shown in Fig 4. Shunt active filters are used to compensate current harmonics of nonlinear loads to perform reactive power compensation and to balance imbalance currents. The matrix converter is considered as one type of load i.e. Current-Source Type of Harmonic Sources. Power electronics converters are a common and typical source of harmonic currents. The distortion of the current waveform, i.e., the generation of harmonics, results from the switching operation. Because the harmonic current contents and characteristic are less dependent upon the AC side, this type of harmonic source behaves like a current source. Therefore, they are called current-source type of harmonic source (or harmonic current source) and represented as a current source. A shunt active filter is to be placed in parallel with a load (matrix converter) to detect the harmonic current of the load and to inject a harmonic current with the same amplitude of that of the load into the AC system. 


\subsection{Analysis of proposed Shunt Active Filter for Matrix Converter}

In order not to lose generality, the harmonic current source is represented as Norton's equivalent circuit. A pure current-source type of harmonic source is a special case of the Norton's equivalent with $\mathrm{Z}_{\mathrm{L}} \quad$.Fig. 4shows the basic principle of a shunt active filter compensating for a harmonic current source, where the harmonic source is represented as Norton's equivalent, $Z s$ is the Source (line) impedance, $I_{L}$ is the equivalent harmonic current source, $Z_{L}$ is the equivalent impedance on the

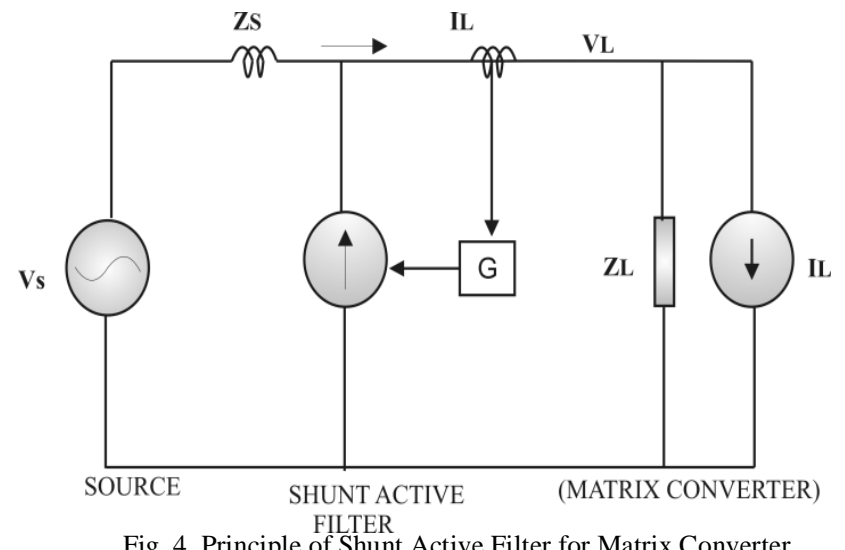

Fig. 4. Principle of Shunt Active Filter for Matrix Converter

input side of matrix converter which may include passive filters and power-factor correction capacitors, and $G$ is the equivalent transfer function of the active filter including the detection circuit of harmonics and the delay of the control circuit. In general, $G$ has the function of notching the fundamental component, that is, $|G|_{h}=0$ at the fundamental, and $|G|_{h}=1$ for harmonics. In the following analysis, all equations are represented in per unit. From Fig. 4, the following equations are obtained.

$$
I_{C}=G I_{L}
$$

$I_{S}=\frac{Z_{L}}{Z_{S}+\frac{Z_{L}}{1-G}} \cdot I_{L O}+\frac{V_{S}}{Z_{S}+\frac{Z_{L}}{1-G}}$

$I_{L}=\frac{\frac{Z_{L}}{1-G}}{Z_{S}+\frac{Z_{L}}{1-G}} \cdot I O+\frac{1}{1-G} \cdot \frac{V_{S}}{Z_{S}+\frac{Z_{L}}{1-G}}$

Focusing on harmonic

$$
\begin{aligned}
& \left.\left|\frac{Z_{L}}{1-G}\right|_{h}\right\rangle\left|Z_{S}\right|_{h} \\
& I_{C}=I_{L h} \\
& I_{L h}=I_{L O h}+\frac{V_{S h}}{Z_{L}}
\end{aligned}
$$

Where, the subscripts, " $h$ " and " $f$ ', represent the harmonic components and the fundamental components respectively. Modulus represents the magnitude of a transfer function. $\mathrm{G}$ can be predesigned and determined by the active filter while $Z s$, and $Z_{L}$ are determined by the system, i.e., parameters of the ac source and the load side of the matrix converter. A shunt active filter senses the load current and injects a current into the system to compensate current harmonics or reactive load. In this paper a shunt filter was used to compensate the current harmonics of matrix converter, here the shunt active filter acts as a current source. The sum of its current and load current is the total current that flows through the source. Therefore, controlling the output current of the active filter can control the source current.

\subsection{Proposed Shunt Active Filter's Control System}

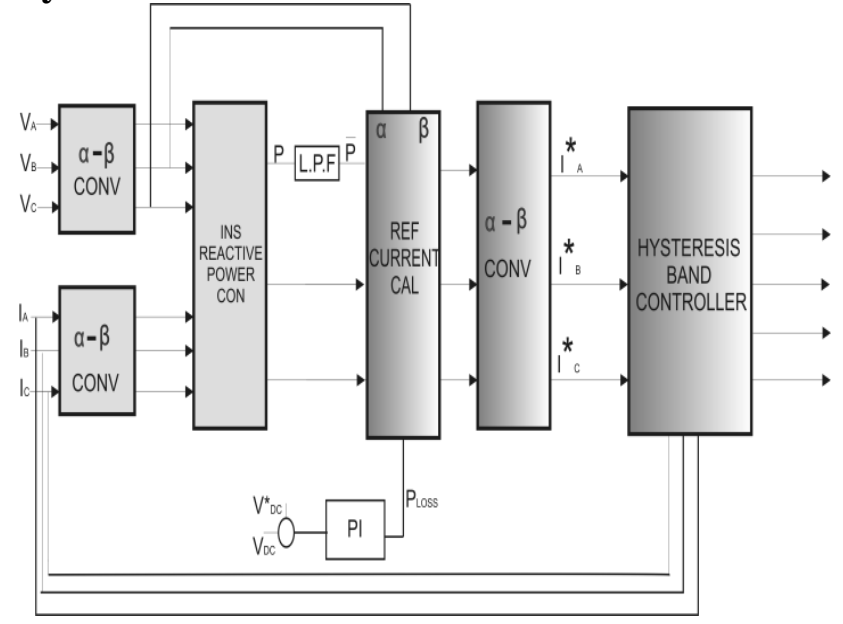

Fig 5: Control system design of Shunt Active Power Filter for matrix converter

The shunt active power filter control algorithm is shown in Fig. 5. Instantaneous reactive power $(p-q)$ theory is used to control of shunt active power filter in real time. In this theory, instantaneous three-phase voltages and current are transformed to $\alpha-\beta-0$ from $a-b$ - $c$ coordinates as shown in equation (12) and (13).

$$
\left[\begin{array}{l}
V_{o} \\
V_{\alpha} \\
V_{\beta}
\end{array}\right]=\sqrt{\frac{2}{3}}\left[\begin{array}{ccc}
\frac{1}{\sqrt{2}} & \frac{1}{\sqrt{2}} & \frac{1}{\sqrt{2}} \\
1 & \frac{-1}{2} & \frac{1}{\sqrt{2}} \\
0 & \frac{\sqrt{3}}{2} & \frac{-\sqrt{3}}{2}
\end{array}\right]\left[\begin{array}{l}
V_{s a} \\
V_{s b} \\
V_{s c}
\end{array}\right]
$$

$$
\left[\begin{array}{l}
I_{O} \\
I_{\alpha} \\
I_{\beta}
\end{array}\right]=\sqrt{\frac{2}{3}}\left[\begin{array}{ccc}
\frac{1}{\sqrt{2}} & \frac{1}{\sqrt{2}} & \frac{1}{\sqrt{2}} \\
1 & \frac{-1}{2} & \frac{1}{\sqrt{2}} \\
0 & \frac{\sqrt{3}}{2} & \frac{-\sqrt{3}}{2}
\end{array}\right]\left[\begin{array}{l}
I_{s a} \\
I_{s b} \\
I_{s c}
\end{array}\right]
$$

Load side instantaneous real and imaginary power components are calculated by using source currents and phase-neutral voltages as given in equation (13). 


$$
\left[\begin{array}{l}
I_{O} \\
I_{\alpha} \\
I_{\beta}
\end{array}\right]=\sqrt{\frac{2}{3}}\left[\begin{array}{ccc}
\frac{1}{\sqrt{2}} & \frac{1}{\sqrt{2}} & \frac{1}{\sqrt{2}} \\
1 & \frac{-1}{2} & \frac{1}{\sqrt{2}} \\
0 & \frac{\sqrt{3}}{2} & \frac{-\sqrt{3}}{2}
\end{array}\right]\left[\begin{array}{l}
I_{s a} \\
I_{s b} \\
I_{s c}
\end{array}\right]
$$

Instantaneous real and imaginary powers includes both $\mathrm{AC}$ and DC components as shown in equation (14). DC components of $p$ and $\mathrm{q}$ is obtained from positive sequence components ( $p$ and $q$ ) of load current. AC components ( $\tilde{\boldsymbol{P}}$ and $\tilde{q}$ ) of $p$ and $q$ include harmonic and negative sequence components of load currents. In order to reduce neutral current, $\mathrm{p}_{0}$ was calculated by using DC and $\mathrm{AC}$ components of imaginary power and $\mathrm{AC}$ component of real power, as given in (15) if both harmonic and reactive power compensation is required

$$
\begin{array}{r}
p_{0}=v_{0} ; p=\bar{p}+\tilde{p} ; q=\bar{q}+\tilde{q} \\
{\left[\begin{array}{l}
i_{s \alpha}^{*} \\
i_{s \beta}^{*}
\end{array}\right]=\frac{1}{v_{\alpha}^{2}+v_{\beta}^{2}}\left[\begin{array}{cc}
v_{\alpha} & -v_{\beta} \\
v_{\beta} & v_{\alpha}
\end{array}\right]\left[\begin{array}{l}
- \\
p+p_{0}+p_{l o s s} \\
0
\end{array}\right]}
\end{array}
$$

$I_{s a}^{*} I_{s b}^{*}$ are reference currents of shunt active power filter in $\alpha$ $\beta-0$ coordinates. To compensate neutral current $i^{*}, s_{0}=-i_{0}$. These currents are transformed to three-phase system as shown below in equation (17)

$$
\left[\begin{array}{c}
i_{s a}^{*} \\
i_{s b}^{*} \\
i_{s c}^{*}
\end{array}\right]=\sqrt{\frac{2}{3}}\left[\begin{array}{ccc}
\frac{1}{\sqrt{2}} & 1 & 0 \\
\frac{1}{\sqrt{2}} & \frac{-1}{2} & \frac{\sqrt{3}}{2} \\
\frac{1}{\sqrt{2}} & \frac{-1}{2} & \frac{-\sqrt{3}}{2}
\end{array}\right]\left[\begin{array}{l}
i_{s 0}^{*} \\
i_{s \alpha}^{*} \\
i_{s \beta}^{*}
\end{array}\right]
$$

The reference currents in three-phase system $\left(i{ }_{s a} i{ }_{s b}\right.$ and $\left.i{ }_{s b}\right)$ are calculated in order to compensate neutral, harmonic and reactive currents in the load. The switching signals used in shunt active power filter control algorithm are generated by comparing reference currents and actual line currents using hysteresis band current control algorithm.

\section{4 .SIMULATION RESULT}

Simulation is carried out on a Matlab /Simulink software and the use of the shunt active filter for matrix converter is evaluated. The simulated SAPF system parameters are given in Table I.

Table 1. SAPF Experimental and Simulation Parameters.

\begin{tabular}{|c|c|c|c|}
\hline & \multicolumn{2}{|c|}{ Parameters } & Value \\
\hline \multirow{2}{*}{ Source } & Voltage & $\mathrm{V}_{\mathrm{Sabc}}$ & 440 \\
& Frequency & $\mathrm{F}$ & $50 \mathrm{~Hz}$ \\
\hline & 3 phase line inductance & $\mathrm{L}_{\mathrm{Labc}}$ & $1 \mathrm{mH}$ \\
\hline Load & &
\end{tabular}

\begin{tabular}{|c|c|c|c|}
\hline & 3 phase load resistance & $\mathrm{R}_{\mathrm{L}}$ & $2 \Omega$ \\
\hline \multirow{3}{*}{ DC link } & Voltage & $\mathrm{V}_{\mathrm{dc}}$ & $1200 \mathrm{v}$ \\
\cline { 2 - 4 } & Capacitor & $\mathrm{C}_{1}, \mathrm{c}_{2}$ & 2200 \\
& & & $\mu \mathrm{F}$ \\
\hline \multirow{3}{*}{ SAPF } & Ac line inductance & $\mathrm{L}_{\mathrm{Cabc}}$ & $.5 \mathrm{mH}$ \\
\cline { 2 - 4 } & Filter resistance & $\mathrm{R}_{\mathrm{Cabc}}$ & $4.7 \Omega$ \\
\cline { 2 - 4 } & Filter capacitor & $\mathrm{C}_{\mathrm{Cabc}}$ & $100 \mu \mathrm{F}$ \\
\cline { 2 - 4 } & Switching frequency & $\mathrm{F}_{\mathrm{pwm}}$ & $20 \mathrm{KHz}$ \\
\hline
\end{tabular}

In the simulation studies, the result are specified before and after SAPF system is operated. In fig (6) the simulations of the matrix converter operates without input capacitor is shown. Hear the line voltage is $440 \mathrm{v}$; the supply current is 200 Amperes. In this simulation the input current wave shape is non-sinusoidal and it contains harmonics. The simulation time start from 0.02 to $0.085 \mathrm{sec}$.Consider the
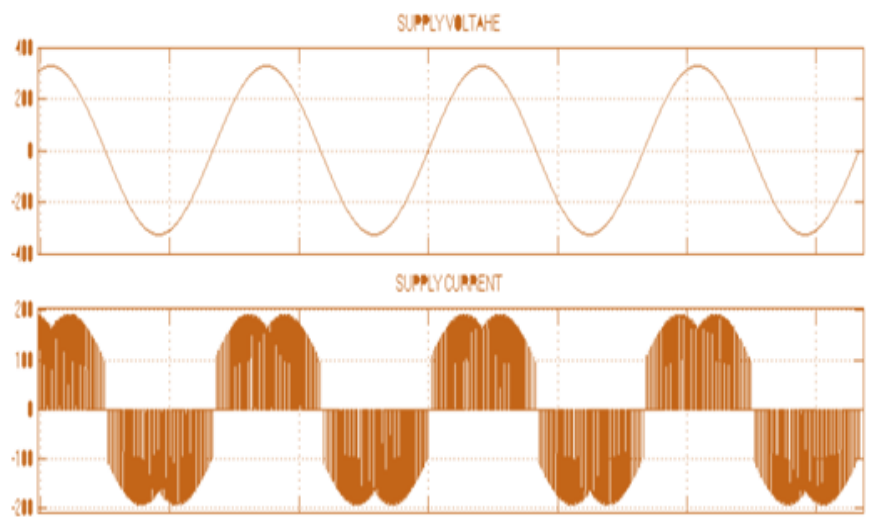

L) VOTAGE

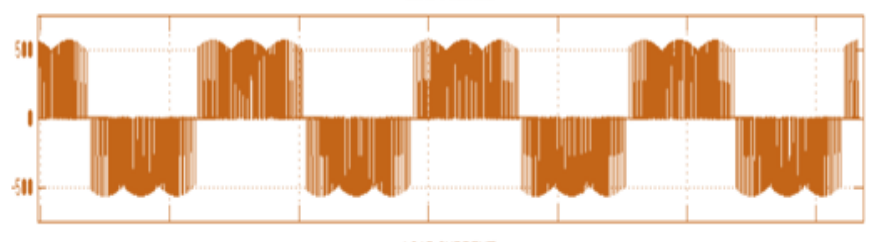

LW CUMENT

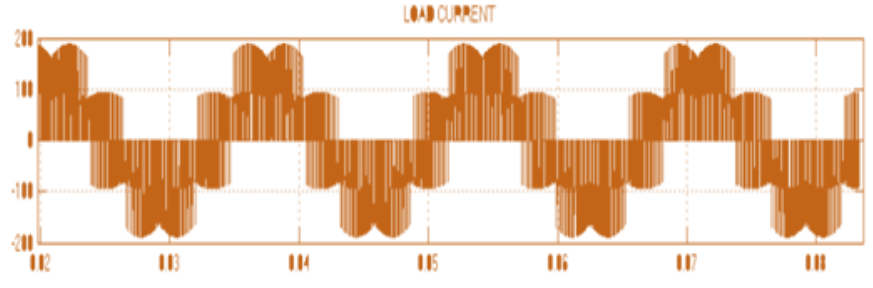

Fig. 6: System voltage $\left(v_{S}\right)$, source current $\left(i_{s}\right)$ load voltage $\left(\mathrm{V}_{\mathrm{L}}\right)$ and load current $\left(\mathrm{I}_{\mathrm{L}}\right)$ without filter.

Simulation time $0.025 \mathrm{sec}$ to $0.045 \mathrm{sec}$ is the one cycle of the current wave form. Here the wave shape of this current is nonsinusoidal and it contains harmonics. 

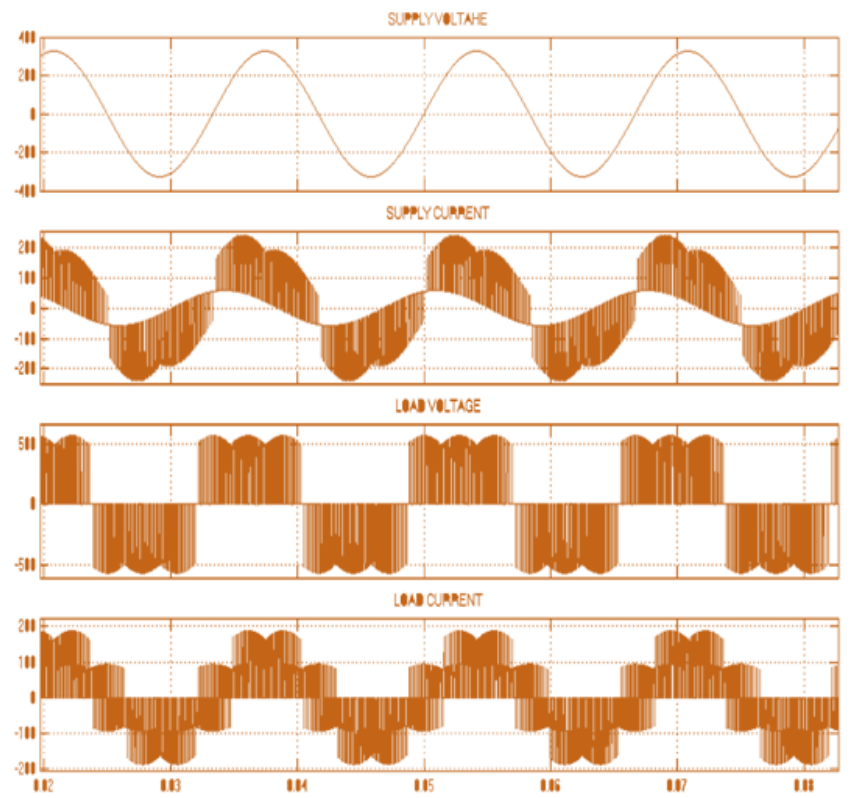

Fig.7: System voltage $\left(v_{S}\right)$, source current $(i s)$ load voltage $\left(\mathrm{V}_{\mathrm{L}}\right)$ and load current $\left(\mathrm{I}_{\mathrm{L}}\right)$ with fixed filter

In the above Fig (7), the simulation of the matrix converter operated with input capacitor is shown. The capacitor value is given in the Table 1.The input current waveform is also non sinusoidal. The harmonics are not effectively eliminated by the fixed capacitor bank and the input current wave farm obtained is non sinusoidal and is given in figure6. Consider the simulation time $0.025 \mathrm{sec}$ to $0.045 \mathrm{sec}$ the current wave form is non sinusoidal and it contain harmonics.
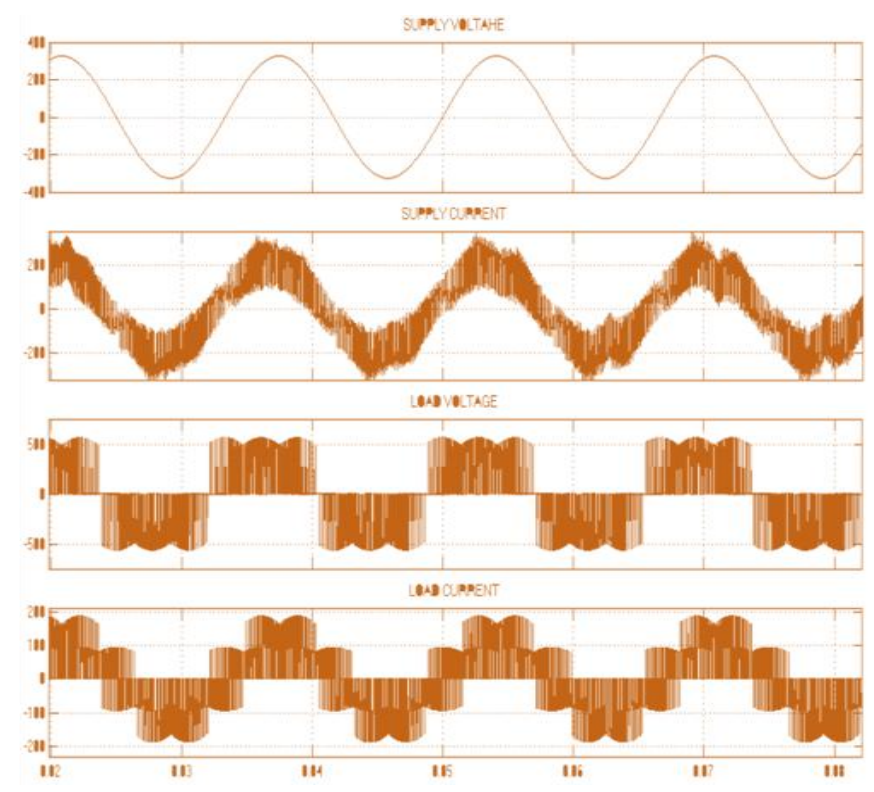

Fig. 8: System voltage $\left(v_{S}\right)$, source current $\left(i_{s}\right)$ loadvoltage $\left(V_{L}\right)$ and load current $\left(I_{L}\right)$ when the shunt active filter is turned on

Fig (8) shows the proposed shunt active power filter scheme that compensates the line current wave shape effectively when compared to the existing system effectively as shown in the simulation results. The total simulation time is $0.02 \mathrm{sec}$ to 0.085 Sec. In this simulation the current waveform is almost sinusoidal. Here Load frequency is $60 \mathrm{~Hz}$..

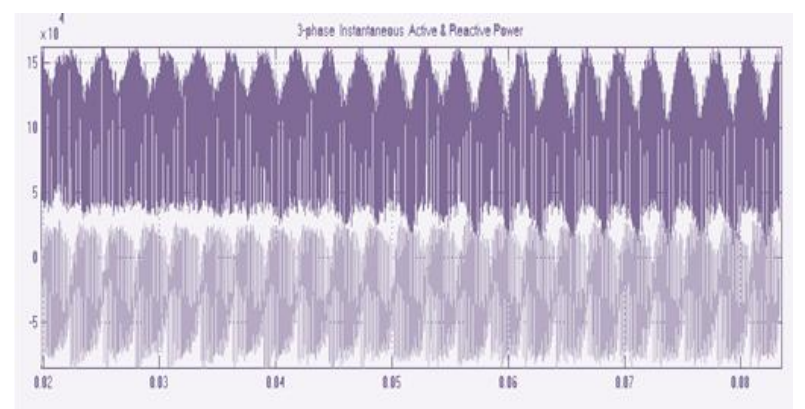

Fig. 9 -Real and Reactive Power without Compensation

Fig.9 shows the input power factor without compensation. Here the reactive power is lagging. In the fig (9) the shunt active filters not only compensate the current harmonics but also It compensates the reactive power as shown in the

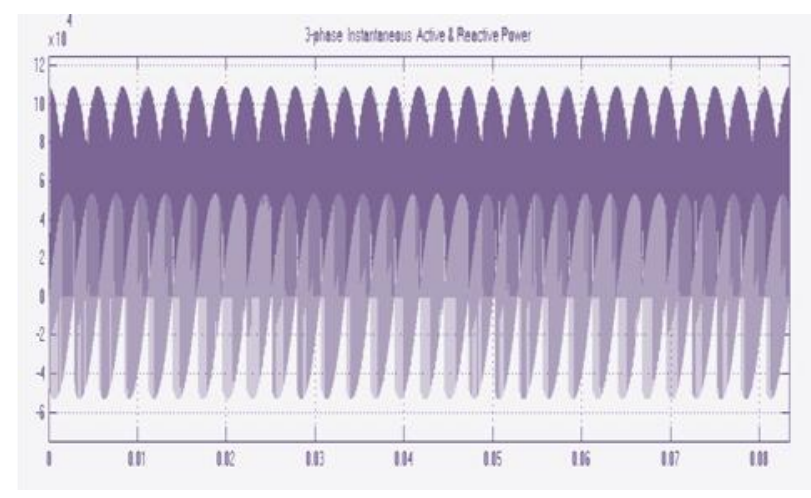

Fig. 10 -real and reactive power without compensation

Simulation result given in Fig .10 shows that the reactive power factor is almost unity.

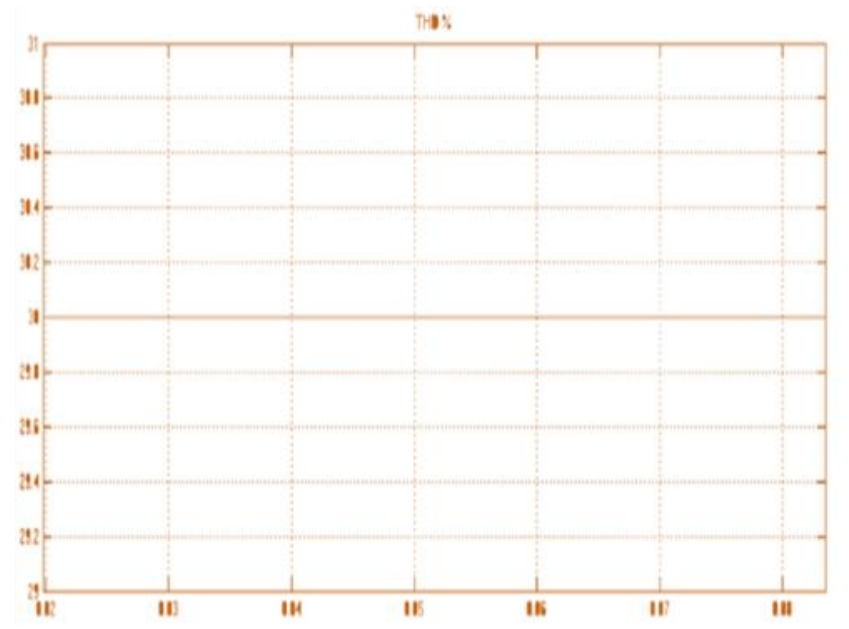

Fig. 11 -Total harmonic Distortion with capacitor 


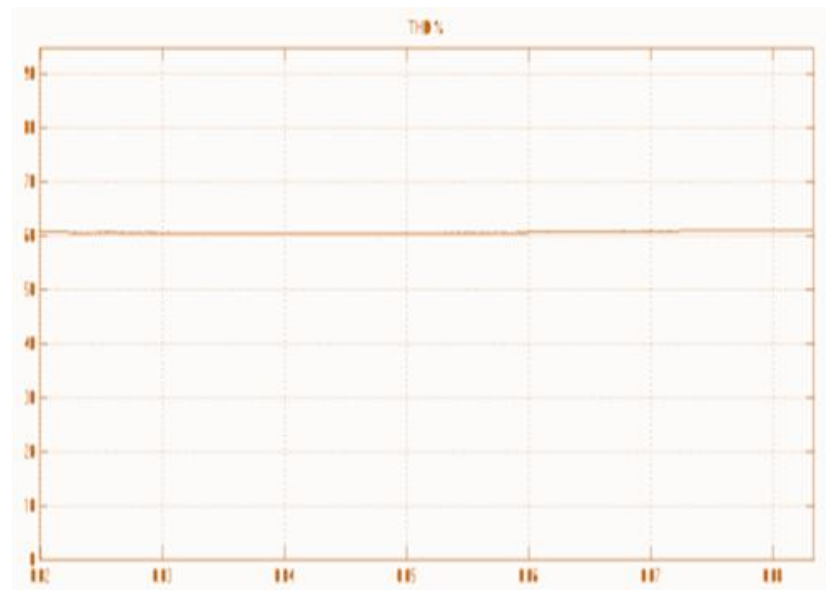

Fig. 12 -Total harmonic Distortion Proposed system

In Fig 11 shows that the supply current harmonics are $60.05 \%$. After the proposed shunt active filter is implemented the supply current harmonics is reduced $30 \%$ as shown in fig (12). So the power quality is maintained by using the shunt active filter.

\section{CONCLUSION}

In this paper shunt active filter method compensation (SAPF) is implemented in the matrix converter for power quality improvement. In simulation studies, the results are specified for the system before the operation of SAPF and after with the inclusion of shunt active filter in the matrix converter. The proposed strategy can restrict up to $30 \%$ of lower, high harmonic components. When SAPF system is operated in matrix converter, the supply harmonics are removed effectively compared to the fixed capacitors. The modification of this proposed methodology has given considerably good simulation results as compared to the conventional harmonic control method. The proposed method is validated and the simulation results are obtained through mat lab/simulink software.

\section{REFERENCES}

[1] Malesani.L, Rossetto.L, Tenti.P, 1992, October. "Optimum Control of N-Input K-Output Matrix Converters," IEEE Transactions on Power Electronics, Vol. 7, no. 4, pp. 707713.

[2] Oliveira.J, and, Yacamini.R, 1978 Sep, "Harmonics produced by direct current converter transformers," Proc. Inst. Elect. Eng, Vol. 125, no. 9, pp.873-878.

[3] Boonchiam .P and Mithulananthan.N, 2006 ,July-Sept. "Understanding of Dynamic Voltage Restorers through MATLAB Simulation," Thammasat Int. J. Sc. Tech., Vol. 11, No. 3.

[4] Alexandrekusko and Thomsom ,1998 "Power Quality in electrical system”. Mc Graw Hill NewYarkchapter1.

[5] Edward, Jian Jiang R, and (Randy) Collins, 2009 "Analysis of Elevated Neutral-to-Earth Voltage in Distribution Systems with Harmonic Distortion" IEEE Transactions on Power Delivery, vol. 24, no. 3, , pp1696-1702.
[6] Ewald F fuchs,mommoh A, Mosoum , 2008 Match . "Power quality in power systems and electrical mechines".pp5, A.P Publication.

[7] HeydtG. T. 1995., Electric Power Quality, 2nd Ed. Scottsdale, AZ: Stars in a Circle, pp34

[8] Ali Emadi B. Bekiarov 2005 "un intrept power supplys and active filter" chapter 2 ,pp65 ,CRCPress NewYark ,.International Standard Book Number 0-8493-3035-1

[9] De La Rosa and Francisco C. 2006 "harmonics and power systems" chapter2,pp30.Copyright by Taylor \& Francis Group, LLC .

[10] EharaM, LeMoneC. P., and NehlL., 1986 "AC adjustable speed application for the cement industry," in Proc. IEEE Cement Industry Technical Conf., Salt Lake City, UT, , pp. $335-362$.

[11] Lobo Heldwein, Kolar,. Johann W, Marcelo 2009 JUNE, "Impact of EMC Filters on the Power Density of Modern Three-Phase PWM Converters" ,IEEE Transactions on Power Electronics, VOL. 24, NO. 6. pp1527-1588.

[12] BielaAlexander Juergen Wirthmueller, Roman Waespe, Marcello Lobo HeldweinKlaus Raggland Johann W. Kolar May 2009 "Passive and Active Hybrid Integrated EMI Filters" IEEEtransactions on power electronics, vol. 24, no. 5, pp1340-1349.

[13] JoosG, ZargariN.R and ZiogasP.D, 1993 "Input Filter Design for PWM Current-Source Rectifiers", Proceedings of Applied Power Electronics Conference and Exposition,APEC'93, pp. 824-830.

[14] Borojevic.D, and Huber.L, 1991 "Input Filter Design of Forced Commutated Cycloconverters", Proceedings of 6th Mediterranean Electrotechnical Conference, , vol.2, pp. 1356-1359.

[15] GrantD.A WheelerP.W and, , ZhangH. 1993. “A theoretical and practical investigation of switching frequency harmonics in a matrix converter," Proceedings of UPEC'93, pp. 502- 505,

[16] JoosG, ZargariN.R, and ZiogasP.D, 1993 "Input Filter Design for PWM Current-Source Rectifiers", Proceedings of Applied Power Electronics Conference and Exposition, APEC'93, pp. 824-830.

[17] BorojevicD, LeeF.C, and VlaktovicV, January 1996 "Input Filter Design for Power Factor Correction Circuits," IEEE Transactions on Power Electronics, Vol. 11, No. 1, pp. 199- 205

[18] Casadei.D, Tani.A., Nielsen.P, and Serra.G, 1997. "Theoretical and experimental analysis of SVMcontrolled matrix converters under unbalanced supply conditions," Electromotion Journal,vol. 4, pp. 28-37. 